\title{
Suicide in pediatrics: epidemiology, risk factors, warning signs and the role of the pediatrician in detecting them
}

\author{
Dario Dilillo ${ }^{1}$, Silvia Mauri2 ${ }^{2 *}$, Cecilia Mantegazza', Valentina Fabiano ${ }^{1}$, Chiara Mameli ${ }^{1}$ and Gian Vincenzo Zuccotti ${ }^{1}$
}

\begin{abstract}
Epidemiological data suggests suicide is uncommon in childhood but becomes an extremely serious issue among adolescents.

Several risk factors have been identified and include the presence of psychiatric illness, a previous suicide attempt, family factors, substance abuse, sexual and physical abuse, disorders in gender identity or bullying. Pediatricians have a primary role in searching for these risk factors, recognizing them and acting synergistically with other specialists to prevent and treat suicidal behavior.

Pediatricians should also be able to identify the "warning signs" for suicide since their presence implies a need for immediate action, as attempted suicide may occur in a few hours or days.

The use of antidepressant drugs and its association with suicidal risk in pediatric age is another topic of ongoing debate. Food and Drug Administration has recently introduced the so-called "black box" on antidepressants' packages with the aim of gaining attention to the possible risk of suicide among adolescents who are treated with antidepressants, with a warning that the risk of suicide is higher when starting a therapy or while adjusting its dosage.
\end{abstract}

Keywords: Suicide, Risk factors, Protective factors, Warning signs, Antidepressive drugs

\section{Introduction}

Suicide is uncommon in children before the age of puberty; subsequently, its frequency tends to increase during adolescence. The pediatrician is involved in either identification or management of young people with suicidal behaviors. On the one hand, the pediatrician should be able to identify the presence of "warning signs" for attempted suicide/suicide in children and/or adolescents. Specifically, the American Academy of Pediatrics (AAP) recommends that a screening for suicide among adolescents should be carried out during visits performed for acute diseases as well as during routine check-ups [1]. On the other hand, the pediatrician should also provide patients with diagnostic and therapeutic support, collaborating with other professionals in order to create a team capable of managing all their different needs.

\footnotetext{
*Correspondence: mauri.silvia@hsacco.it

${ }^{2}$ Department of Pediatrics, Luigi Sacco Hospital, University of Milan, Milan, Italy

Full list of author information is available at the end of the article
}

\section{Review}

\section{Epidemiology}

Most of the epidemiological data on suicide in pediatric age comes from American studies.

Prevalence of attempted suicide among adolescents has changed over the years: whereas a reduction was reported in the period from 2001 to 2008 ( $8.8 \%-7.8 \%)$, on the contrary, an increase was subsequently observed in the 2009-2011 two-year period (6.3 \% $-7.8 \%)$. On average, it is estimated that approximately 2 million adolescents are attempting suicide every year, 700.000 subjects in this age group request healthcare after an attempted suicide, 2.000 adolescents die [2]. Recent data from the Youth Risk Behavior Surveillance [3] shows that in 2011, $15.8 \%$ of students between the ages of 14 and 18 years have considered suicide, $7.8 \%$ have attempted suicide and $2.4 \%$ have necessitated medical care afterwards. It is also estimated that while the attempted suicide is twice as frequent among females compared to males, death by suicide is more frequent among males than in females $(9.4 / 100.000$ versus $2.7 / 100.000)$. In 
addition, although the prevalence of death by suicide among adolescents remains low (0.006 \%), suicide represents the third leading cause of death among subjects aged between 13 and 19 years, and the second leading cause of death among those aged between 10 and 24 years [4]. In Italy, suicide in the youngest represents one of the leading cause of death among people between the ages of 15 and 24; in 2007, 154 boys between the ages of 14 and 24 died because of suicide [5]. There are no specific Italian databases for the detection of attempted suicide; approximately, it is estimated that the ratio between attempted suicide and suicide in the youngest is 200:1. A recent italian study investigated the trends in the prevalence of suicide from January 2011 to December 2013 by sex and age; fifty-five suicide deaths among young people aged less than 18 years of age were identified, suicide rates were higher among Italians than foreign children/adolescents (8.16 times higher); the most frequent known cause of suicide was conflict in a romantic relationship, followed by bullying [6]. Epidemiologic data regarding suicide in pre-adolescents are scarce. Pelkonen et al. [7] reported a rate of suicide of 0.5 per 100.00 for females and of 0.9 per 100.00 for males amongst 5-14-year-olds. Dervic et al. [8] estimated a mean rate of suicide in children and young adolescents up to 14 years of age of approximately $0.6 / 100.00$ worldwide, with a male-female ratio of 2:1. Childhood affective and disruptive disorders and abuse were the most often reported psychiatric risk factors. A recent French retrospective study [9] has analyzed the data from 48 subjects aged less than 13 years, who were hospitalized from 2008 to 2011 after attempted suicide in a department of child psychiatry. Attempted suicide was more frequent among the female subjects compared to males ( $\mathrm{F}: \mathrm{M}=26: 22$ ). Age-specific differences were also reported: subjects who attempted suicide aged more than 12 years were predominantly females, whereas children attempting suicide under 12 years of age were predominantly males. Patients younger than 11 years had used more violent means to attempt suicide.

\section{The role of Pediatrician}

Prevention of suicide is an extremely challenging issue for the healthcare providers. Some literature data reports that, in adulthood, the victims of suicide had often visited their doctor before attempting suicide [10]. Considering the increased incidence of suicide in adolescence, the pediatrician plays a vital role in assessing the level of risk by clinical judgment, by reviewing the risk and protective factors and by a direct verification of thoughts and acts of suicide. Moreover, the pediatrician plays a fundamental role in the field of education [1]. A recent American study [11] evaluating perception and ideas on suicide in 66 adolescents and 30 parents, showed that both categories recognized it as one important issue, but not a matter of significance to them. In addition, both adolescents and their parents recognized factors including mental illness, substance and alcohol abuse, as well as social difficulties, as common risk factors for suicide. However, parents also considered that transient phases of alcohol and substances abuse may be considered normal in adolescence. Both groups expressed the need to be informed and educated on the topic of suicide. It is evident that the pediatrician role is more complex than simply performing a screening for suicide: he/she should encourage families to address such issues as well as being involved in educational programs.

Even if there are no specific tests to identify subjects susceptible to suicide, risk factors must be investigated by the pediatrician and taken into consideration [12] (Table 1). Risk factors include:

- Psychiatric illness. Literature data shows that approximately $90 \%$ of adolescents who commit suicide are suffering from a psychiatric disorder (in particular humor disorder), and more than $60 \%$ of young people are depressed at the time of death [13]. A meta-analysis conducted in 2006 on 60.000 adolescents aged between 13 and 18 years old, estimated a prevalence of more than $5.6 \%$ of subjects with depression (females $>$ males) [14]. Moreover, some authors suggest that up to $20 \%$ of adolescents have a depressive episode during the course of their life [15]. The Diagnostic and Statistical Manual of Mental Disorders (DSMV) [16] shows that children compared to adolescents have a greater difficulty in representing their internal states and they show depression through behavioral and somatic symptoms (abdominal pain, constipation, headache) and through irritable mood; adolescents instead show symptoms that are more similar to those experienced by adults such as depressed mood, loss of interest in daily activities, weight loss/gain and insomnia/hypersomnia (Table 2) [1]. In addition, some signs of depression can be noticed by teachers at school and must be investigated by the attending physician (Table 3). The process of screening for depression in pediatric age and adolescence is highly controversial: the disease can cause adverse effects both in the short term life of a child/adolescent and in the long term future life as an adult. In 2005 a Canadian Task Force stated that there is enough evidence to support the benefit of routine health screening for depression in these age groups [17]. However, in 2009 a US Task Force [18] argued that adolescents, but not children, should be screened for depression in primary care centers, when accurate diagnosis, psychotherapy and followups are ensured. Nowadays the problem still remains open. Although the screening for depression is viewed as the only alternative to a complete indifference to the problem, many authors argue that investing resources in therapeutic programs rather than in screening would be 
Table 1 Risk factors for suicide among adolescents

\begin{tabular}{|c|c|c|c|}
\hline Demographic & Clinical & Family and environmental & Mental State \\
\hline - Male sex & $\begin{array}{l}\text { - Psychiatric illness (major depression, bipolar } \\
\text { disorder, conduct disorder) }\end{array}$ & - Particularly stressful events & - Thoughts on suicide \\
\hline - Older age & - Recent discharge from a psychiatric hospital & - Availability of lethal means & $\begin{array}{l}\text { - Abuse of alcohol or illegal } \\
\text { substances }\end{array}$ \\
\hline \multirow[t]{9}{*}{ - Non heterosexual } & - Previous attempted suicide & - Lack of social support & $\begin{array}{l}\text { - State of anxiety, agitation, being } \\
\text { without hope }\end{array}$ \\
\hline & - Family history of depression or suicide & $\begin{array}{l}\text { - Contact with subjects with suicidal } \\
\text { behaviors }\end{array}$ & - Impulsiveness \\
\hline & - Physical/sexual abuse & - Loss of a parent (death/divorce) & - Difficulty in troubleshooting \\
\hline & - History of trauma in childhood & - Difficult relationship with parents & \\
\hline & - Sleep disorders & $\begin{array}{l}\text { - Perception of excessive control/poor care } \\
\text { by parents }\end{array}$ & \\
\hline & $\begin{array}{l}\text { - Organic pathologies that determine functional } \\
\text { limitations }\end{array}$ & - Bullying & \\
\hline & - Personality disorders & & \\
\hline & - Low self-esteem & & \\
\hline & - Low compliance to therapy & & \\
\hline
\end{tabular}

Adapted from Gordon M, Melvin G. Risk assessment and initial management of suicidal adolescents. Aust Fam Physician. 2014;43(6):367-72

preferable. In addition, very little is known about the possible positive effects of a screening program, while there is a fear that an increase in diagnosis without welldefined treatment guidelines could lead to a significant increase in prescription of antidepressant drugs without adequate programs of follow-up [19].

- Previous attempted suicide. Literature data shows that a prior history of suicidal or parasuicidal behavior (attempts of suicide, past exposure to suicidal risk without a declared suicidal intention) represents an important risk factor for suicide. Self-injurious behaviors, defined as attitudes to cause direct and deliberate harm to oneself (eg non- suicidal self-injury, suicidal behavior and suicide) [20], are of health concern. Data from literature estimates that between $13 \%$ and $29 \%$ of adolescents engage in nonsuicidal self-injury (self-cutting, burning, biting without lethal intent). Instead, suicidal behaviors (suicide attempt, sucide) refer to direct self-injurious behaviors with the

Table 2 Symptoms and signs of depression in the pediatric age

- Irritability and/or depressed mood
- Loss of interest in everyday activities
- Psychomotor agitation and/or loss of energy
- Low concentration and indecision
- Insomnia and/or hypersomnia
- Loss and/or increase in body weight
- Loss of hopes and sense of powerlessness
- Feelings of guilt and low self-esteem
- Chronic somatic symptoms, which do not respond to common
therapies (headache, addominalgia, constipation)
- Thoughts of death and/or suicide

intent to end one's life such as hanging/strangulation, jumping from heights and severe cutting. Non suicidal self injury and suicidal behavior differ in the following: intention (individuals who engage in non suicidal selfinjury do not desire to end their life), lethality and frequency (high letality methods with low frequency in suicidal behaviors). Attempted suicide affects $4-10 \%$ of the case-subjects aged less than 15 years, and $54 \%$ of the case-subjects under 24 years [21]. In the years of adolescence attempted suicide is approximately twice as frequent in females than in males; moreover $30 \%$ of the subjects who have attempted suicide during adolescence will try again within 4 years [21]. Other studies report that $42 \%$ of the adolescents who have attempted suicide will pursue it again within 2 years [22]. The repetition of an attempted suicide appears to be associated mainly with psychiatric disorders, particularly major depression, and difficulty in adjusting the emotions. Although several studies on

Table 3 Signs of depression at school
- Frequent absences
- Excessive delays
- Low concentration
- Difficulty in performing the tasks assigned
- Crying in class
- Difficulty in adapting to changes
- Poor participation in school activities
- Difficulty of interaction with companions
- Provocative attitude
- Restlessness and nervousness
- Isolation and muteness 
repeated attempted suicide have been conducted, there is little data on prognostic factors that can predict the risk of recurrence. A study on adolescents with a history of single or multiple attempted suicides reports that subjects who have tried several times to commit suicide often show a related desire to die in their attempts, and regret to have not been able to complete their act; however, in this study, the specific characteristics of the attempted suicide that can predict a future attempt are not analyzed [23]. In particular it would be useful to understand if any change or escalation in the methods used to attempt suicide could provide any information to establish the likelihood of completing the act. A study on 1397 adults who completed suicide showed that the methods they had used in the previous attempts of suicide were less lethal [24]. A recent study [25] on 54 adolescents who attempted suicide has analyzed prognostic factors for recurrence of the act; $33 \%$ of the subjects repeated suicide and the more indicative prognostic factors were: living alone, expressing a strong and real desire of dying, planning the act for an hour or more. When a child or an adolescent is admitted to the Emergency Room after having attempted suicide, the pediatrician must be able to assess the risk of repetition of this act. The subjects whose characteristics are listed in Table 4 may be recognized at an increased risk for recurrence and should always be hospitalized and subjected to a psychiatric evaluation [21].

Before discharging the patient, the pediatrician should always recommend parents to remove weapons or potentially lethal drugs from home and to limit the access to alcohol or other substances with disinhibitory effects as much as possible. In addition, it is very important to make sure that the child/adolescent has a figure of support at home, and to ensure the family plan an adequate follow-up [21].

- Family factors. Familiarity for suicidal behaviors is a risk factor for suicide regardless of the presence of psychiatric illnesses. For this reason, the pediatrician should investigate and take into consideration any strife in the family, loss of a family member (divorce/ death), possible abuse or relationship difficulties between parents and children [21]. In particular, a recent review [26] showed a close association between suicidal behaviors and a parent/child relationship characterized by poor care or overprotection.

- Substance abuse. Abuse of drugs and alcohol should always be investigated, since it increases the possibility of suicide, especially among male adolescents with humor disorders [27]. A recent study [28] examined the correlation between attempted suicide and "Heavy Episodic Drinking" (HED), a phenomenon increasingly observed among young people: HED increases the risk of suicide by 2.6 times in children under 13 years and by 1.2 times in subjects aged more than 18 years. Moreover, another study showed that drinking alcohol when one feels "low" increases the risk of attempted suicide by 3 times [29].

- Sexual and physical abuse. Sexual and physical abuse are important risk factors for suicidal behavior or suicidal ideation, especially in subjects aged between 16 and 25 years [21]. A recent study [30] showed that $50 \%$ of women and $33 \%$ of men who attempted suicide experienced physical or sexual abuse or domestic violence. Interventions to reduce the incidence of abuse or violence in pediatric age may represent a form of suicide prevention in adulthood [30].

- Sexual orientation. The pediatrician should also assess the sexual orientation of adolescents who are at risk of suicide. Literature shows that young homosexual men are 2-3 times more likely to commit suicide compared to their heterosexual peers [31].

In particular, those living in families that refuse their sexual orientation have a risk of suicide 8 times greater than those whose sexual orientation is accepted by the family [32].

- Bullying. It was reported that both "bullies" and "victims" of bullying are at an increased risk of suicidal behaviors [21]. In fact "bullies" are naturally more exposed to legal issues (criminal behaviors, including the use of drugs), and are at risk of developing an antisocial personality disorder. Being the victim of bullying affects mental growth in terms of selfesteem and personal well-being, and may lead to the development of depressive syndromes or of anorexia nervosa in predisposed individuals [33].

Table 4 Risk Factors for recurrence of attempted suicide

\begin{tabular}{lc}
\hline Case history: & Demographic data: \\
- Constant thoughts of suicide & - Living alone \\
- Previous attempted suicide & - Male gender \\
\hline Mental state: & - Depression, mania, hypomania, anxiety, or all of these mental states \\
- Substance abuse & - Irritability, agitation, hallucinations, violent attitude
\end{tabular}

Adapated from: Shaffer D, Pfeffer CR et al. Practice parameter for assessment and treatment of children and adolescents with suicidal behavior. J Am Acad Child Adolesc Psychiatry. 2001; 40(7 Supplement): 24S-51S) 
- Finally, safety of the home environment should also be taken into consideration [12]; environmental precautions are aimed at restricting access to means of suicide (eg guns, ropes, medications), and family members should be aware of the risks related to the situation [34]. In particular literature supports the importance of education in injury prevention: Kruesi [35] showed that educating parents in this field in the emergency room, leads to actions such as limiting the access to lethal means, for example locking up their firearms. On the other hand Brent [36] demonstrated that parents of depressed adolescents are frequently noncompliant with recommendations to remove firearms from the home. Restriction of access to means for suicide is a fundamental suicide prevention strategy in adolescents. Limiting availability of firearms in countries with high prevalence of suicide by shooting is mandatory: presence of firearms in households increases the risk of adolescent suicide and restriction of their availability reduces this risk [37]. Limiting availability of storage of pesticides in rural areas of developing countries, where suicide by pesticide ingestion is common, has also been suggested [38] In addition limiting the availability of pack sizes of drugs that are commonly used for selfpoisoning in young people, such as paracetamol, is imperative [39].

Along with risk factors, pediatricians should also investigate also the presence of protective factors (Table 5) [31].

Thereafter, if suicidal ideation is suspected, the following specific questions should be investigated:

1) Have you ever thought to kill yourself or would you rather be dead?

2) Have you ever done something with the purpose to do yourself harm or kill yourself?

3) Have you ever considered methods to put an end to your existence?

Although direct questions can cause anxiety for the doctor, it is important to know that investigations about suicidal ideation do not induce such ideas in the patient

Table 5 Protective factors against suicide at a young age

\begin{tabular}{l}
\hline - Access to services of mental hygiene \\
- Positive connections with the school \\
- Family stability \\
- Religious involvement \\
- Lack of access to deadly weapons \\
- Recognition of the importance of behavior intended to research of the \\
aid of adults \\
- Good relations with their peers \\
- The ability to solve problems and overcome adversity \\
\hline
\end{tabular}

[40]. Instead, it is of vital importance to understand the real need for immediate action [41]. The pediatrician must consider warning signs as they can provide information about the current psychophysical state of the patient. Warning signs must be differentiated from the risk factors and what best differentiates them is the temporal relationship with the risk of suicide. Alarm signals help in identifying subjects who may attempt suicide in subsequent minutes, hours or days, while risk factors identify the possibility of suicide in the long term (weeks or years) [41]. Over the years, several attempts have been made to define these alarm signals; in 2006 the American Association of Suicidology [42] published a Consensus that can be applied in clinical practice: the sentence "IS PATH WARM" is useful to recall the main "warning signs" (Table 6). It is also important to differentiate the need for immediate assistance (Table 7), not only for the pediatrician, but also for educators, teachers, family, and the same adolescents.

Finally, a very debated theme is the use of antidepressant drugs in pediatric age, literature and long-term data for this is lacking. After a post hoc analysis that showed a significant increase in suicidal behaviors in patients treated with paroxetine, the FDA conducted a metaanalysis [43] in which data of 24 clinical trials in 4.400 pediatric patients suffering from major depression, obsessive compulsive disorder and other psychiatric disorders treated with antidepressants were analyzed. The results showed an increase in suicidal ideation during

Table 6 Consensus warning signs of suicide

A person at risk for suicidal behavior most often will exhibit warning signs such as:

I Ideation Expressed or communicated ideation

Threatening to hurt or kill him/herself or talking of wanting to hurt or kill him/herself

Looking for ways to kill him/herself by seeking access to firearms, available pills or other means

Talking or writing about death, dying or suicide when these actions are out of the ordinary

$S$ Substance Increased substance (alcohol or drug) use abuse

P Purposelessness No reasons for living; no sense of purpose in life

A Anxiety Anxiety, agitation, unable to sleep or sleeping all

T Trapped Feeling trapped - like there's no way out

H Hopelessness Hopelessness

W Withdrawal Withdrawing from friends, family and society

A Anger Rage, uncontrolled anger, seeking revenge

$\mathrm{R}$ Recklessness Acting reckless or engaging in risky activities, seemingly without thinking

M Mood changes Dramatic mood changes

Adapted from: American Association of Suicidology. How do you remember the warning signs of suicide? Newslink 2006; 32:20 
Table 7 Consensus warning signs of suicide

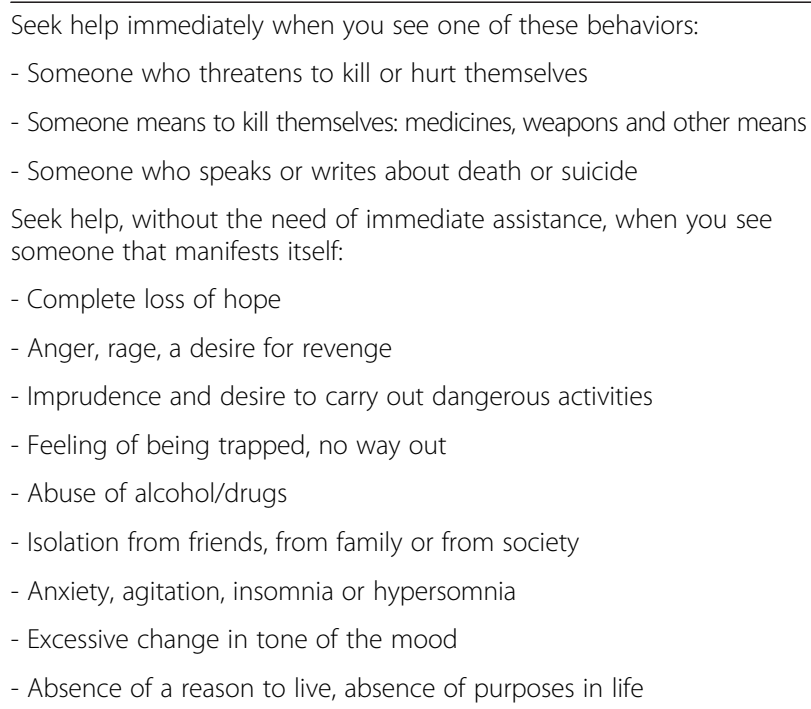

the first months of therapy in patients treated with antidepressants respect to placebo ( $4 \%$ versus $2 \%$ ) but no suicide brought to term. On 15th October 2004 [44], the Food and Drug Administration ordered all the pharmaceutical companies to add a warning black box on all packages of antidepressants recommending the following: "All pediatric patients following a therapy with antidepressants for any disease should be closely monitored by evaluating a possible worsening of symptoms/signs of suicidal behaviors or any changes in behavior, in particular in the first months of therapy, or if they are implementing changes of dosage. Ideally, the patient should be evaluated once a week for the first 4 weeks, then every other week for the next 4 weeks, and then 12 weeks after the initiation of therapy. If clinically indicated the patient should also be evaluated after 12 weeks. Furthermore, in the time interval between visits, it would be advisable to contact the patient by phone in order to get information about his state of health". Retrospectively, some Authors [45] showed that the analysis conducted by the FDA had some limitations: firstly, adverse effects were only studied for a short period of time, secondly, drugs were not assessed individually, and thirdly, not all the methods used to assess the risk of suicide had been approved for pediatric patients. A recent review [45] has therefore analyzed the consequences of the introduction of the "black box" in the packages of antidepressants. The first noticeable result, starting from 2005, was the reduction in the number of subjects diagnosed with depression in pediatric age both in the USA and in Europe. Secondly, up to 2004, the prescription of antidepressant drugs in the pediatric age had presented a significant increase, both in the United States and in some countries in Europe; however from 2005 onwards, the number of prescriptions has shown a significant reduction, especially among pediatricians, doctors of general medicine and, to a lesser extent, psychiatrists; the review also showed that a high percentage of parents refused antidepressant treatment for their siblings [46]. Studies have also shown that, after the introduction of the "black box", doctors pay greater attention in monitoring patients on antidepressants, especially in the first weeks of therapy [47]. In addition, some Authors [48] reported an increase in the number of suicides among children and adolescents in the period post "black box", assuming then an association with the reduction of prescription of antidepressant drugs. This issue still remains highly controversial and long-term studies are needed to fully evaluate the efficacy and safety of antidepressant drugs in pediatric age and their possible association with suicidal events. However, the American Academy of Child and Adolescent Psychiatry and the American Psychiatric Association [49] recommend a careful monitoring of pediatric patients even at home, by encouraging parents to contact their physician in the event of an outbreak of the signs/symptoms summarized in Table 8 .

\section{Conclusions}

The data reported highlights the fundamental role of the pediatrician in the management of the child/adolescent with suicidal behavior. He/she should be able to investigate the presence of mood disorders, suicidal thoughts, sexual orientation and other factors related to suicide, and educate those who live and work with young people (for example parents and teachers) to recognize the risk factors for suicide, with a particular focus on patients with chronic illnesses. In addition, the pediatrician should be able to collaborate with other professionals (e.g., psychiatrists) involved in the care of patients at risk for suicide or attempted suicide, should be aware of the balance between benefits and risks of administering antidepressant drugs, and should monitor the patients whilst on treatment, in particular when starting antidepressant and after any dose-changing.

Table 8 Alarm signals whilst on antidepressant therapy

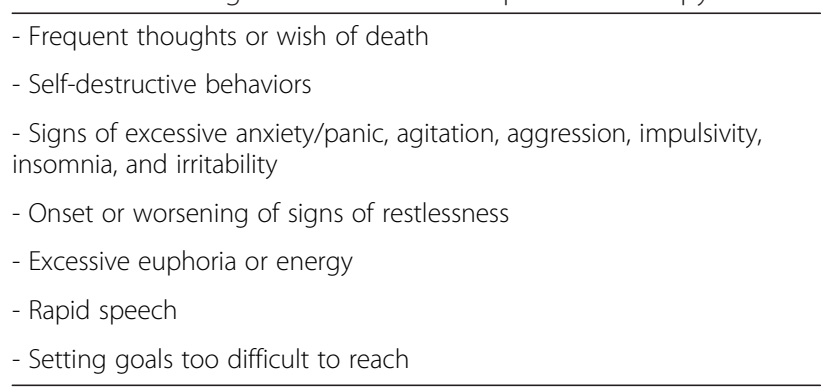

Adapted from: American Psychiatric Association, 2001 


\section{Competing interests}

The authors declare that they have no competing interests.

\section{Authors' contributions}

SM, CM, VF, CM wrote the manuscript; DD and GVZ critically revised the entire manuscript. All author read and approved the final manuscript.

\section{Author details}

${ }^{1}$ Department of Pediatrics, Ospedale dei Bambini V. Buzzi, University of Milan, Milan, Italy. ${ }^{2}$ Department of Pediatrics, Luigi Sacco Hospital, University of Milan, Milan, Italy.

Received: 26 January 2015 Accepted: 16 June 2015

Published online: 07 July 2015

\section{References}

1. Shain BN. Suicide and suicide attempts in adolescents. Pediatrics. 2007;120(3):669-76.

2. American Academy of Child and Adolescent Psychiatry. Practice parameter for the assessment and treatment of children and adolescents with suicidal behavior. J Am Acad Child Adolesc Psychiatry. 2001;40 Suppl 7:24-51.

3. Centers for Disease Control and Prevention. Youth risk behavior surveillance-United States. MMWR. 2012;61:11-2. Accessed 10 Sept 2014.

4. Centers for Disease Control and Prevention, National Centers for Injury Prevention and Control, Web-based Injury Statistics Query and Reporting System (WISQARS). Leading causes of death, United States. 2013. www.cdc.gov/injury/wisqars/leading_causes_death.html. Accessed 10 Sept 2014.

5. ISTAT. http://www.istat.it/it/archivio/suicidi. Accessed 10 Sept 2014

6. Ferrara P, lanniello F, Cutrona C, Quintarelli F, Vena F, Del Volgo V, Caporale O, Malamisura M, De Angelis MC, Gatto A, Chiaretti A, Riccardi R. A focus on recent cases of suicides among Italian children and adolescents and a review of literature. Ital J Pediatr. 2014:40:69.

7. Pelkonen M, Marttunen M. Child and adolescent suicide: epidemiology, risk factors, and approaches to prevention. Paediatr Drugs. 2003;5:243-65.

8. Dervic K, Brent DA, Oquendo MA. Completed suicide in childhood. Psychiatr Clin North Am. 2008:31(2):271-91.

9. Berthod C, Giraud C, Gansel Y, Fourneret P, Desombre H. Tentatives de suicide chez 48 enfants a'ge's de 6 a' 12 ans Suicide attempts of 48 children aged 6-12 years. Arch Pediatr. 2013;20:1296-305.

10. McDowell AK, Lineberry TW, Bostwick JM. Practical suicide-risk management for the busy primary care physician. Mayo Clinic Proc. 2011;86(8):792-800.

11. Schwartz KA, Pyle SA, Dowd MD, Sheehan K. Attitudes and beliefs of adolescents and parents regarding adolescents suicide. Pediatrics. 2010;125:221-7.

12. Gordon M, Melvin G. Risk assessment and initial management of suicidal adolescents. Aust Fam Physician. 2014;43(6):367-72.

13. Gould MS, Greenberg T, Velting DM, Shaffer D. Youth suicide risk and preventive interventions: a review of the past 10 years. J Am Acad Child Adolesc Psychiatry. 2003:42:386-405.

14. Costello EJ, Erkanli A, Angold A. Is there an epidemic of child or adolescent depression? J Child Psychol Psychiatry. 2006:47:1263-71.

15. Lewinsohn PM, Rohde P, Seeley JR. Major depressive disorder in older adolescents: prevalence, risk factors, and clinical implications. Clin Psychol Rev. 1998;18:765-94.

16. American Psychiatric Association. Diagnostic and statistical manual of mental disorders. 5th ed. Washington: American Psychiatric Association; 2013.

17. MacMillan HL, Patterson CJ, Wathen CN, Feightner JW, Bessette P, Elford RW, Feig DS, Langley J, Palda VA, Patterson C, Reeder BA, Walton R. Canadian task force on preventive health care: screening for depression in primary care: recommendation statement from the Canadian task force on preventive health care. CMAJ. 2005;172:33-5.

18. US Preventive Services Task Force. Screening and treatment for major depressive disorder in children and adolescents: US Preventive Services Task Force recommendation statement. Pediatrics. 2009;123:1223-8.

19. Thombs BD, Roseman M, Kloda LA. Depression screening and mental health outcomes in children and adolescents: a systematic review protocol. Sys Rev. 2012;1:58.

20. Hamza CA, Stewart SL, Willoughby T. Examining the link between nonsuicidal self-injury and suicidal behavior: A review of the literature and an integrated model. Clin Psychol Rev. 2012;32:482-95.
21. Shaffer D, Pfeffer CR. Practice parameter for assessment and treatment of children and adolescents with suicidal behavior. J Am Acad Child Adolesc Psychiatry. 2001:40 Suppl 7:24-51.

22. Bridge JA, Goldstein TR, Brent DA. Adolescent suicide and suicidal behavior. J Child Psychol Psychiatry. 2006;47:372-94

23. Miranda R, Scott M, Hicks R, Wilcox HC, Harris Munfakh JL, Shaffer D. Suicide attempt characteristics, diagnoses, and future attempts: comparing multiple attempters to single attempters and ideators. J Am Acad Child Adolesc Psychiatry. 2008;47:32-40.

24. Isometsa ET, Lonnqvist JK. Suicide attempts preceding completed suicide. Br J Psychiatry. 1998;173:531-5.

25. Miranda R, De Jaegere E, Restifo K, Shaffer D. Longitudinal follow-up study of adolescents who report a suicide attempt: aspects of suicidal behavior that increase risk of a future attempt. Depress Anxiety. 2014;31:19-26.

26. Goschin S, Briggs J, Blanco-Lutzen S, Cohen LJ, Galynker I. Parental affectionless control and suicidality. J AffectDis. 2013;151:1-6.

27. Shafii M, Steltz-Lenarsky J, Derrick AM, Beckner C, Whittinghill JR. Comorbidity of mental disorders in the post-mortem diagnosis of completed suicide in children and adolescents. J Affect Disord. 1998;15(3):227-33.

28. Aseltine RH, Schilling EA, James A, Glanovski JL, Jacobs D. Age variability in the association between heavy episodic drinking and adolescent suicide attempts: findings from a large-scale, school-based screening program. J Am Acad Child Adolesc Psychiatry. 2009;48(3):262-70.

29. Schilling EA, Aseltine RH, Glanovsky JL. Adolescent alcohol use, suicidal ideation, and suicide attempts. J Adolesc Health. 2009;44(4):335-41.

30. Afifi TO, Enns MW, Cox BJ, Asmundson GJ, Stein MB, Sareen J. Population attributable fractions of psychiatric disorders and suicide ideation and attempts associated with adverse childhood experiences. Am J Public Health. 2008;98(5):946-52.

31. King M, Semlyen J, Tai SS, Killaspy H, Osborn D, Popelyuk D, Nazareth I. A systematic review of mental disorder, suicide, and deliberate self harm in lesbian, gay and bisexual people. BMC Psychiatry. 2008;18(8):70.

32. Kann L, Olsen E, McManus T. Sexual identity, sex of sexual contacts and health-risk behaviors among students in grades 9-12- youth risk behavior surveillance, selected sites, United States, 2001-2009. Cent Dis Control Prev MMWR. 2011;60:7.

33. Barker ED, Arseneault L, Brendgen M, Fontaine N, Maughan B. Joint development of bullying and victimization in adolescence: relations to delinquency and self-harm. J Am Acad Child Adolesc Psychiatry. 2008;47(9):1030-8.

34. Wasserman D, Rihmer Z, Rujescu D, Sarchiapone M, Sokolowski M, Titelman D, Zalsman G, Zemishlany Z, Carli V. The European Psychiatric Association (EPA) guidance on suicide treatment and prevention. European Psychiatry. 2012;27:129-41.

35. Kreusi MJP, Grossman J, Pennington JM, Woodward PJ, Duda D, Hirsch JG. Suicide and violence prevention: parent education in the emergency department. J Am Acad Child Adolesc Psychiatry. 1999;38(3):250-5.

36. Brent DA. The aftercare of adolescents with deliberate self-harm. J Child Psychol Psychiatry. 1997;38:277-86.

37. Brent $D$, Bridge J. Firearms availability and suicide: evidence, interventions and future directions. Am Behav Sci. 2003;46:1192-210.

38. Pearson M, Konradsen F, Gunnell D, et al. A community-based cluster randomised trial of safe storage to reduce pesticide self-poisoning in rural Sri Lanka: study protocol. BMC Public Health. 2011;11:879.

39. Hawton K, Simkin S, Deeks J. UK legislation on analgesic packs: before and after study of long term effect on poisonings. BMJ. 2004;329:1076.

40. Bajaj P, Borreani E, Ghosh P, Methuen C, Patel M, Crawford MJ. Screening for suicidal thoughts in primary care: the views of patients and general practitioners. Ment Health Fam Med. 2009:4:229-35.

41. Rudd MD. Suicide warning signs in clinical practice. Curr Psych Rep. 2008;10:87-90.

42. American Association of Suicidology. How do you remember the warning signs of suicide? Newslink. 2006:32:20.

43. Hammad TA, Laughren T, Racoosin J. Suicidality in pediatric patients treated with antidepressant drugs. Arch Gen Psychiatry. 2006;63:332-9.

44. Kondro W. FDA urges "black box" warning on pediatric antidepressant. CMAJ. 2004;171(8):837-8

45. Adegbite-Adeniyi C, Gron B, Rowles BM, Demeter CA, Findling RL. An update on antidepressant use and suicidality in pediatric depression. Expert Opin Pharmacother. 2012;13(15):2119-30.

46. Bhatia SK, Rezac AJ, Vitiello B, Sitorius MA, Buehler BA, Kratochvil CJ. Antidepressant prescribing practices for the treatment of children and adolescents. J Child Adolesc Psychopharmacol. 2008;18:70-80. 
47. Cheug A, Sacks D, Dewa CS, Pong J, Levitt A. Pediatric prescribing practice and the FDA black box warning on antidepressants. J Dev Behav Pediatr. 2008:29:213-5.

48. Gibbons RD, Brown CH, Hur K, Markus SM, Bhaumik DK, Erkens JA, Herngs RM, Mann JJ. Early evidence on the effects of regulators' suicidality warnings on SSRI prescriptions and suicide in children and adolescents. Am J Psychiatry. 2007;164:1356-63.

49. American Psychiatric Association and American Academy of Child and Adolescent Psychiatry. The use of medication in treating childhood and adolescent depression: information for physicians.

www.parentsmedguide.org/physiciansmedguide. Accessed 9 October 2006

\section{Submit your next manuscript to BioMed Central} and take full advantage of:

- Convenient online submission

- Thorough peer review

- No space constraints or color figure charges

- Immediate publication on acceptance

- Inclusion in PubMed, CAS, Scopus and Google Scholar

- Research which is freely available for redistribution 